\title{
Spatio-temporal patterns of drought in North Xinjiang, China, 1961-2012 based on meteorological drought index
}

\author{
WU Yanfeng ${ }^{1}$, Batur BAKE ${ }^{1 *}$, ZHANG Jusong $^{2}$, Hamid RASULOV $^{3}$ \\ ${ }^{1}$ College of Grassland and Environmental Science, Xinjiang Agricultural University, Urumqi 830052, China; \\ ${ }^{2}$ College of Agronomy, Xinjiang Agricultural University, Urumqi 830052, China; \\ ${ }^{3}$ Faculty of Hydrometeorology, Tajik Agrarian University, Dushanbe 734003, Tajikistan
}

\begin{abstract}
Drought, which is one of the most frequently occurring severe hazards with long time scales and covering wide geographical areas, is a natural phenomenon resulting in significant economic losses in agriculture and industry. Drought is caused by an imbalance between the inputs of and the demand for water which is insufficient to meet the demands of human activities and the eco-environment. As a major arid and semi-arid area and an important agricultural region in Northwest China, North Xinjiang (NX) shows great vulnerability to drought. In this paper, the characteristics of inter-annual and seasonal drought were analyzed in terms of drought occurrence and drought coverage, by using the composite index of meteorological drought and the data of daily precipitation, air temperature, wind speed, relative humidity and sunshine duration from 38 meteorological stations during the period 1961-2012. Trend analysis, wavelet analysis and empirical orthogonal function were also applied to investigate change trend, period and regional characteristics, respectively. In NX, annual and seasonal drought occurrence and drought coverage all showed a decreasing trend that was most significant in winter (with rates of -0.26 month/10a and $-15.46 \%$, respectively), and drought occurrence in spring and summer were more frequent than that in autumn and winter. Spatially, drought was severe in eastern regions but mild in western regions of NX. Annual and seasonal drought occurrence at 38 meteorological stations displayed decreasing trends and were most significant in "Shihezi-Urumqi-Changji", which can help to alleviate severe drought hazards for local agricultural production and improve human livelihood. NX can be approximately classified into three sub-regions (severe drought region, moderate drought region and mild drought region), which were calculated from annual drought frequencies. The cross wavelet transform suggested that SOI (Southern Oscillation Index), AOI (Arctic Oscillation Index), AAOI (Antarctic Oscillation Index), PAOI (Pacific/North American Oscillation Index) and NAOI (North Atlantic Oscillation Index) have significant correlation with the variation of drought occurrence in NX. To prevent and mitigate the occurrence of drought disasters in NX, agricultural and government managers should pay more attention to those drought events that occur in spring and summer.
\end{abstract}

Keywords: drought; spatio-temporal pattern; drought indices; North Xinjiang

Citation: WU Yanfeng, Batur BAKE, ZHANG Jusong, Hamid RASULOV. 2015. Spatio-temporal patterns of drought in North Xinjiang, China, 1961-2012 based on meteorological drought index. Journal of Arid Land, 7(4): 527-543. doi: 10.1007/s40333-015-0125-x

The significant influence of climate change on natural and human systems has attracted substantial attention all over the world in recent years (Katz and Brown, 1992; Liu et al., 2012). The Fifth Report of the Intergovernmental Panel on Climate Change (Stocker,
2014) indicated that the global terrestrial and ocean temperature increased by $0.89^{\circ} \mathrm{C}$ from 1901 to 2012 and by $0.72^{\circ} \mathrm{C}$ from 1951 to 2012 , respectively. Global warming caused variation of water circulation, and spatio-temporal patterns of water resources have

*Corresponding author: Batur BAKE (E-mail: baturbake@xjau.edu.cn)

Received 2014-09-17; revised 2015-01-14; accepted 2015-02-06

(C) Xinjiang Institute of Ecology and Geography, Chinese Academy of Sciences, Science Press and Springer-Verlag Berlin Heidelberg 2015 
significantly influenced drought and wet conditions and the balance between supply of and demand for water resources in arid inland areas (Easterling et al., 2000; Sheffield et al., 2012). Increasing in drought intensity and frequency during the past 50 years seriously threatened agricultural production and natural ecosystems in China (Yu et al., 2014; Zhang et al., 2014). North Xinjiang (NX), as a typical arid and semi-arid area in Central Asia, has a larger demand of irrigation water, which accounts for $90 \%$ of the total water consumption. The temperature and precipitation have increased significantly at the rates of $0.35^{\circ} \mathrm{C} / 10 \mathrm{a}$ and $11.2 \mathrm{~mm} / 10 \mathrm{a}$ over the past 50 years under global warming, respectively (Xu et al., 2014). Drought results in severe damage to agriculture, the economy and the environment, with characteristics of high frequencies, long-time scales and wide geographical areas in NX. Therefore, it is imperative to conduct researches on spatio-temporal patterns and possible causes of drought to alleviate the negative effects of drought on human society and the environment of NX.

During the past century, various drought indicators have been proposed and modified to quantify drought by detecting and evaluating drought events ( $\mathrm{Li}$ et al., 2014). Many indicators, such as the Palmer Drought Severity Index (Palmer, 1965), Surface Water Supply Index (Shafer, 1982), Standardized Precipitation Index (SPI) (McKee et al., 1993, 1995; Wang et al., 2012) and Relative Moisture Index (MI) (Cao et al., 2013), are widely used to monitor and analyze regional and global drought and wet variation. These indicators are not adequate to capture variations in drought occurrence, because these variations result from many elements and are significantly influenced by evaporation and precipitation in arid and semi-arid areas ( $\mathrm{Li}$ et al., 2014). The composite index (CI), provided by the National Climate Center of China, is extensively used for provincial meteorological monitoring and can precisely and efficiently monitor and evaluate variations of regional drought (Liu et al., 2012; Xie et al., 2013; Zhang et al., 2013). The CI is based on a combination of meteorological variables, such as precipitation and evaporation, and is calculated at short time scales (1 month) and for a multi-scale SPI (3 months).

NX is located in the arid and semi-arid Northwest
China and suffers heavily from drought hazards that largely threaten the local ecological environment and economical development. Accompanied by increasing precipitation in NX, the humidification trend became more significant (Zhao et al., 2010; Wang et al., 2013; $\mathrm{Xu}$ et al., 2014). However, the increasing potential evaporation resulted from increasing temperature may counteract the positive effect of humidification, which may cause the increase and magnification of drought events (Dai et al., 2013; Vicente-Serrano et al., 2014). Thus, the study of drought changes in NX is attracting increasingly attentions (Shi et al., 2002; Jiang et al., 2004; Zhao et al., 2012). Previous studies have investigated the change trend of drought-wetness based on homogenized drought-wetness index of precipitation and evaporation and studied drought variation based on Standardized Precipitation Index, Precipitation Anomalies Percentage or Palmer Drought Severity Index (Zhuang et al., 2010; Yang et al., 2012; Pan et al., 2013; Zhang et al., 2014). However, most of the above studies investigated variations of drought only based on precipitation or the combination of precipitation and temperature, and obtained different results. In addition, some drought indices had limited timescales, for instance, the timescales of the Palmer Drought Severity Index are mainly from 8 to 12 months (Keyantash et al., 2002). However, former researchers have seldom applied the CI method to further study drought variations in NX. In the present study, we used $\mathrm{CI}$ as the drought index to detect and characterize the spatio-temporal variations of drought occurrence in NX. The objectives of this study are (1) to explore the periodicity and tendency of drought occurrence and drought coverage area in NX from 1961 to 2012, and (2) to detect the spatio-temporal drought occurrence and investigate the possible meteorological and oscillation factors of drought variations in NX.

\section{Study area and data analysis}

\subsection{Study area}

The study area is located at $43^{\circ} 23^{\prime}-49^{\circ} 10^{\prime} \mathrm{N}$, $79^{\circ} 57^{\prime}-91^{\circ} 32^{\prime} \mathrm{E}$ in China (Fig. 1), and covers an area of $5.95 \times 10^{5} \mathrm{~km}^{2}$, including Junggar Basin, Yili Valley, Bortala Valley, Tacheng Valley, Beitashan region and the northern slope of the Tianshan Mountains. The 


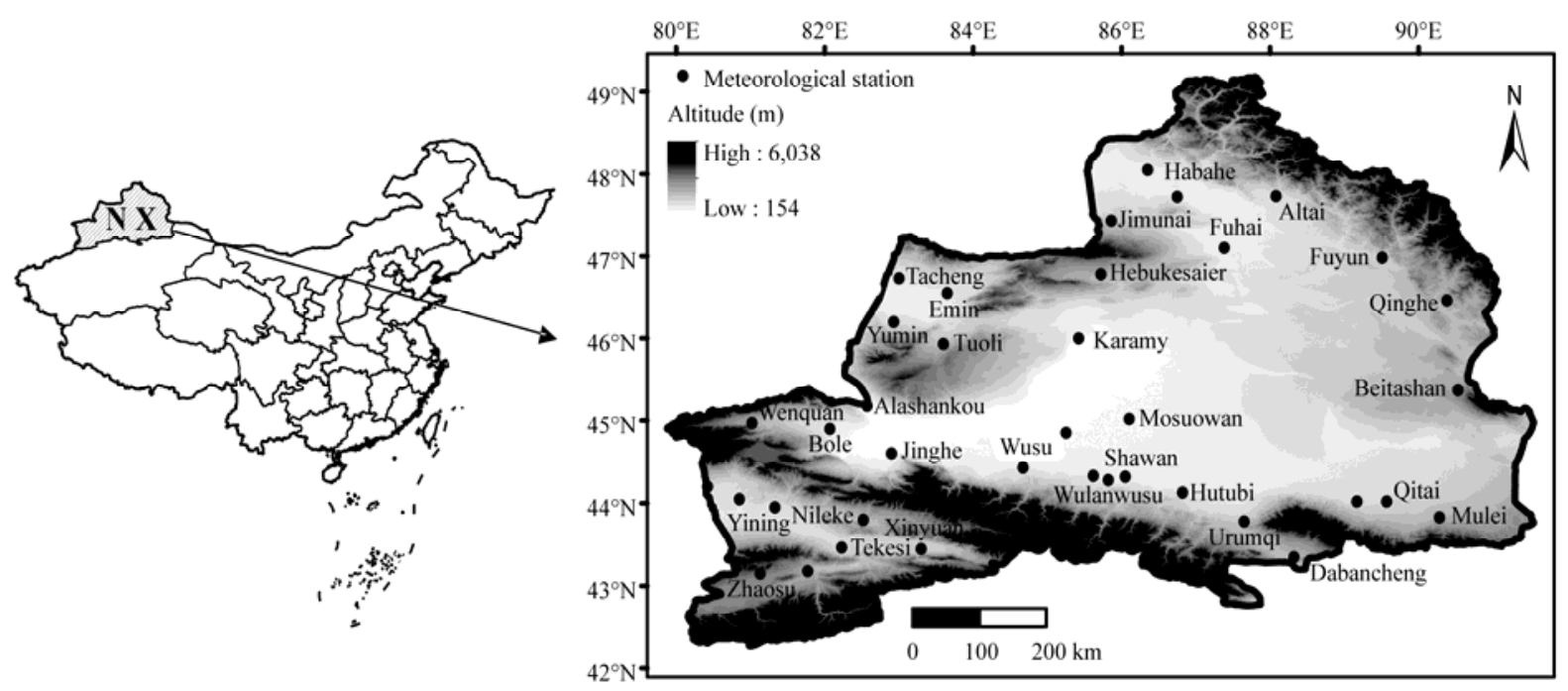

Fig. 1 Location of North Xinjiang in China (left) and spatial distribution of meteorological stations in North Xinjiang (right). NX, North Xinjiang.

region is characterized by a typical Central Asian desert climate, influenced not only by the Atlantic Ocean and westerly winds, but also by local terrains such as in the Yili Valley, Emin Valley and Ertix River Valley, which have more rain in spring and more snow in winter. The annual precipitation ranges from 150 to $250 \mathrm{~mm}$. NX has abundant light and heat resources: $\geq 10^{\circ} \mathrm{C}$ annual accumulated temperature is $3,500-4,500^{\circ} \mathrm{C}$ and the average annual evaporation is $1,000-1,600 \mathrm{~mm}$.

\subsection{Data source}

Meteorological data included daily precipitation (P), mean temperature $\left(\mathrm{T}_{\text {mean }}\right)$, maximum temperature $\left(\mathrm{T}_{\max }\right)$, minimum temperature $\left(\mathrm{T}_{\min }\right)$, sunshine duration $(\mathrm{SD})$, relative humidity (RH) and wind speed (WS) of 38 meteorological stations in NX from 1961 to 2012 (Fig. 1), which were collected from the National Climate Center of China (http://cdc.cma.gov.cn/home.do) and responsible for primary quality control. Monthly data of the South Oscillation Index (SOI), Arctic Oscillation Index (AOI), Antarctica Oscillation Index (AAOI), North Atlantic Oscillation Index (NAOI) and Pacific/North American Oscillation Index (PAOI) also came from the National Climate Center of China. For seasonal analysis, each year was divided into four seasons, spring (March to May), summer (June to August), autumn (September to November) and winter (December to February of the following year). The availability of an effective and dense network of ground meteorologi- cal stations measuring a wide range of climate and hydrologic variables makes NX highly suitable for testing the change trend of drought occurrence under global warming.

\subsection{Methods}

The analysis of spatio-temporal patterns of drought during 1961-2012 in NX was conducted by the following steps: (1) The daily precipitation, mean temperature, maximum temperature, minimum temperature, sunshine duration, relative humidity and wind speed obtained from 38 meteorological stations were arithmetically averaged or summed up for providing monthly calculation of SPI1, SPI3 (Eq. 1), potential evaporation and relative moisture index. (2) The times of annual and seasonal drought occurrence of 38 stations were calculated based on Eq. 1 and classification criteria in Table 1, with one drought means the CI value of a month lesser or equal to -0.6 . (3) On the basis of the results of drought occurrence at 38 stations, the annual and seasonal drought coverage and arithmetic mean value of drought occurrence in NX were calculated for the past 52 years. (4) Trend analysis, wavelet analysis, empirical orthogonal function (EOF) and rotated empirical orthogonal function (REOF) were also applied to investigate the change trend, period and spatial patterns of drought occurrence based on arithmetic mean value of annual and seasonal drought occurrence and drought coverage, respectively (Gong et al., 2013; Zhang et al., 2013; Cao et al., 2014). The spatial analysis of the times of 
Table 1 Levels of the meteorological drought composite index $(\mathrm{Cl})$

\begin{tabular}{cll}
\hline Level & Type & Composite index \\
\hline 1 & Normal & $\mathrm{CI}>-0.6$ \\
2 & Mild drought & $-1.2<\mathrm{CI} \leq-0.6$ \\
3 & Moderate drought & $-1.8<\mathrm{CI} \leq-1.2$ \\
4 & Severe drought & $-2.4<\mathrm{CI} \leq-1.8$ \\
5 & Extreme drought & $\mathrm{CI} \leq-2.4$ \\
\hline
\end{tabular}

drought occurrence and EOF mode were interpolated by Kriging method of ArcGIS software (version 10.2). The temporal analysis, such as wavelet analysis, EOF and REOF, were conducted by MATLAB (version 2013b). (5) A more powerful and common method of continuous wavelet analysis was applied to examine the annual drought occurrence and annual Oscillation Index (SOI, AOI, AAOI, PAOI and NAOI) that may be expected to be linked in some way (Valdes Galicia et al., 2007; Yang et al., 2008).

The CI, which was constructed based on SPI at multiple scales, relative moisture index (MI) and precipitation amount, is commonly used for regional meteorological monitoring (Liu et al., 2012; Xie et al., 2013; Zhang et al., 2013). It can be calculated as follows:

$$
\mathrm{CI}=\mathrm{a} \times \mathrm{SPI} 1+\mathrm{b} \times \mathrm{SPI} 3+\mathrm{c} \times \mathrm{MI} .
$$

Where SPI1 is the SPI calculated by the recent one-month precipitation, SPI3 is the SPI calculated by the precipitation of recent three months, and MI is calculated by monthly precipitation and monthly evaporation. The parameters $\mathrm{a}, \mathrm{b}$ and $\mathrm{c}$ were taken as 0.4, 0.4 and 0.8, respectively (Liu et al., 2012; Xie et al., 2013; Zhang et al., 2013). MI can be calculated as follows:

$$
\mathrm{MI}=(\mathrm{P}-\mathrm{E}) / \mathrm{E} .
$$

Where $\mathrm{P}$ is monthly precipitation and $\mathrm{E}$ is monthly potential evaporation. The Penman-Monteith (PM) equation was used to calculate monthly E.

In this study, the monthly CI values of 38 stations from 1961 to 2012 were calculated using Eq. 1. The classification criteria of $\mathrm{CI}$ in China are shown in Table 1. Drought coverage (D) was calculated as $\mathrm{D}=\mathrm{D}_{\mathrm{n}} / \mathrm{D}_{\mathrm{N}}$, where $\mathrm{D}_{\mathrm{n}}$ is the number of the meteorological stations with drought occurrence and $D_{N}$ means the total number of meteorological stations.

\section{Results and discussion}

\subsection{Temporal variation of drought coverage}

2.1.1 Characteristics of seasonal and inter-annual drought coverage change

Seasonal and inter-annual drought coverage in NX all exhibit decreasing trends (Fig. 2). It can be seen that spring, summer, autumn, winter and inter-annual drought coverages were decreased by $-4.43 \% / 10 \mathrm{a}$, $-4.90 \% / 10 \mathrm{a}, \quad-1.33 \% / 10 \mathrm{a}, \quad-15.47 \% / 10 \mathrm{a} \quad$ and $-0.67 \% / 10 \mathrm{a}$, respectively. The decreasing trend for winter reached the significance level $P<0.01$, the decreasing trends for spring and summer reached the significance level $P<0.05$, and the decreasing trends for autumn and inter-annual drought coverage did not reach the significance level $(P<0.05)$. Obviously, inter-annual drought coverage was higher than the four separate seasonal drought coverages. The average percentage of inter-annual drought coverage was $97.06 \%$ for the past 52 years, during which NX was all covered by drought for 37 years and the relative minimum values of $63.15 \%$ and $76.31 \%$ occurred in 1992 and 1998, respectively. The drought coverage for the 1990s was $92.63 \%$, much lower than those for the 1960s, 1970s, 1980s and 2000s.

The average drought coverages for summer and autumn were $77.68 \%$ and $78.64 \%$, which were larger than those for spring and winter $(67.05 \%$ and $44.45 \%$, respectively). However, drought covered the entire NX for 12 years in spring, 11 years in summer, 9 years in autumn and only 3 years in winter, which indicated that drought was more serious in spring and summer in the entire NX, and regional drought was more serious in autumn. The value of drought coverage for spring was high in the 1980s but lower in the 2000 s. The value of drought coverage for summer was high in the 1970s but lower in the 1990s and 2000s. The value of drought coverage for autumn was high in the 1970s and 2000s but lower in the 1980s. The value of drought coverage for winter was high in the 1960s but lower in the 1990s.

In summary, the decreasing tendency of drought coverage was evident in NX. With respect to seasonal changes, the decreasing tendency was identified mainly in winter. Whereas, drought also occurred frequently and has massive influence on agriculture, ecology and environment. 

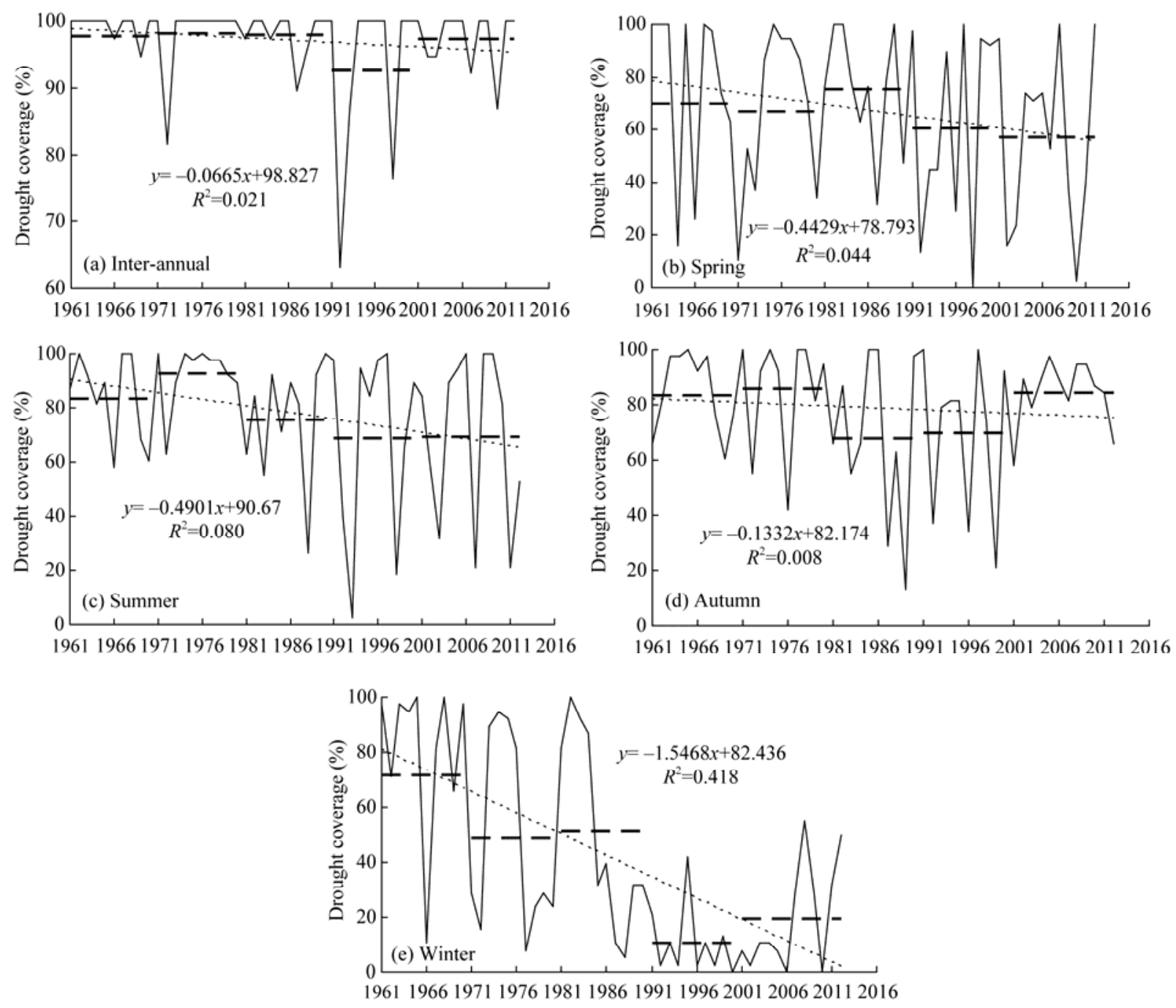

Fig. 2 Variation of inter-annual (a) and seasonal (spring (b), summer (c), autumn (d) and winter (e)) drought coverage during the period of 1961-2012. The dotted lines represent the linear trend, the dashed lines the decadal variation, and the solid lines the inter-annual variation.

\subsubsection{Periodic analysis of inter-annual and seasonal drought coverage}

A robust method was proposed, under which the real parts of the drought coverage signals were transformed with Morlet wavelet analysis. The fluctuation of real parts was consistent with original signals of drought coverage. The contour center is the center of high or low value of original signals. Figure 3 shows the time-frequency distributions of the real part of the Morlet wavelet analysis and the wavelet variances in the inter-annual and seasonal drought coverage in NX. Figure $3 \mathrm{a} 1$ shows that inter-annual drought coverages have periods of 22-28 and 12-17 years, which developed intensively in the 1960s. Clearly, the only one peak value corresponds to the 27-year cycle (Fig. 3a2), which sug- gests that the major cycle of inter-annual drought coverage changes over 27-year cycles during the past 52 years. The drought coverage of spring demonstrates 13-year and 7-year cyclical fluctuations, which developed intensively in the 2000s (Figs. 3b1 and b2). The drought coverage of summer presented a major period of 27 years during the past 52 years, and the second cyclical period was 10a, which developed intensively in the 1960s (Figs. $3 \mathrm{c} 1$ and $\mathrm{c} 2$ ). The drought coverage of autumn presented a major period of 13 years during the past 52 years, and the second period was 27 years from 1975 to 2012, which developed intensively in the 1960s (Figs. $3 \mathrm{~d} 1$ and d2). However, the drought coverage of winter presented no major period during the past 52 years, but presented a 13-year period during 1961 to 1987 (Figs. 3e1 and e2). 


\subsection{Spatio-temporal pattern of inter-annual and seasonal drought occurrence}

2.2.1 Temporal characteristics of drought occurrence

The inter-annual drought occurrence presented decreasing
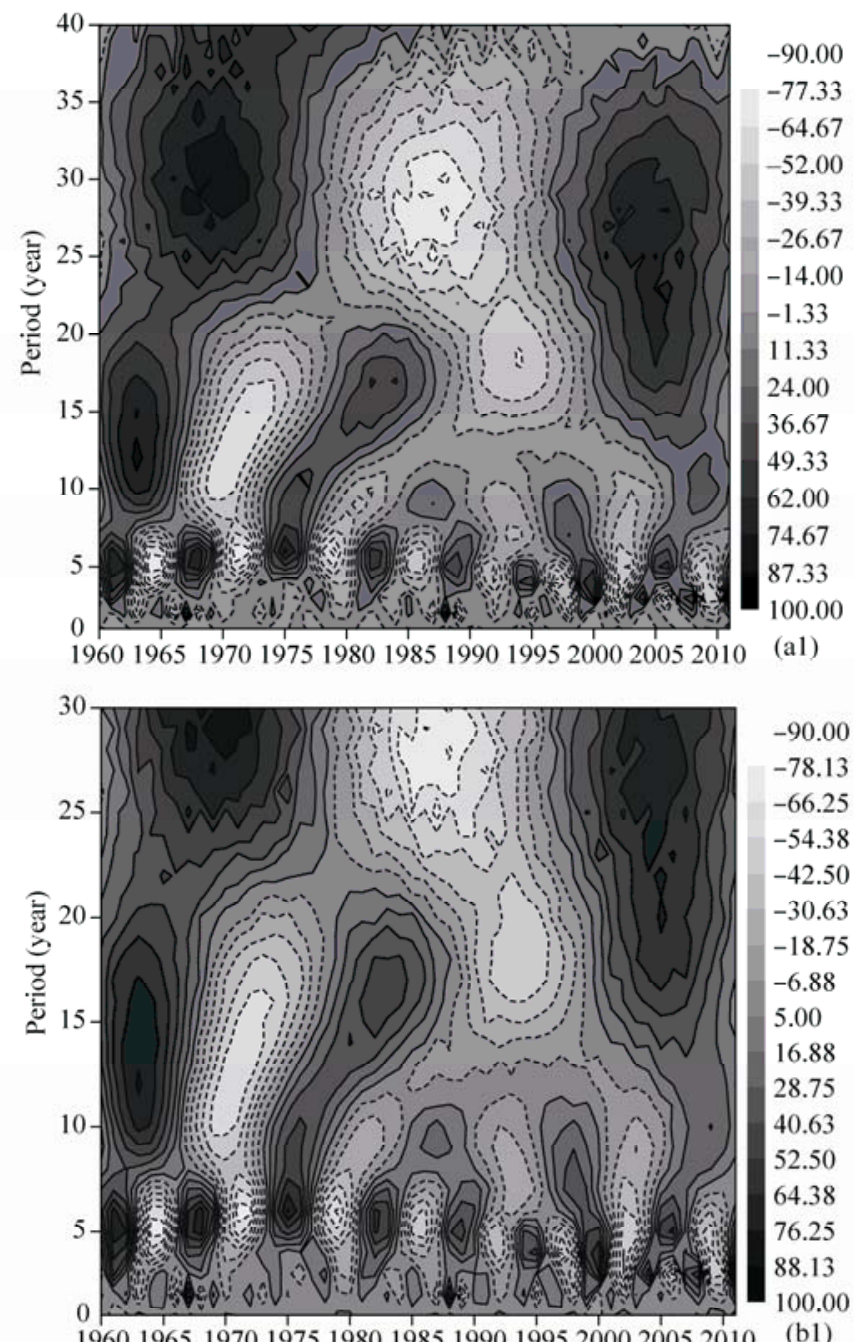

$-90.00$

$-78.13$

$-66.25$

$-54.38$

$-42.50$

$-30.63$

$-18.75$

$-6.88$

5.00

16.88

28.75

40.63

52.50

64.38

76.25

88.13

100.00

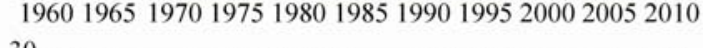

(b1)

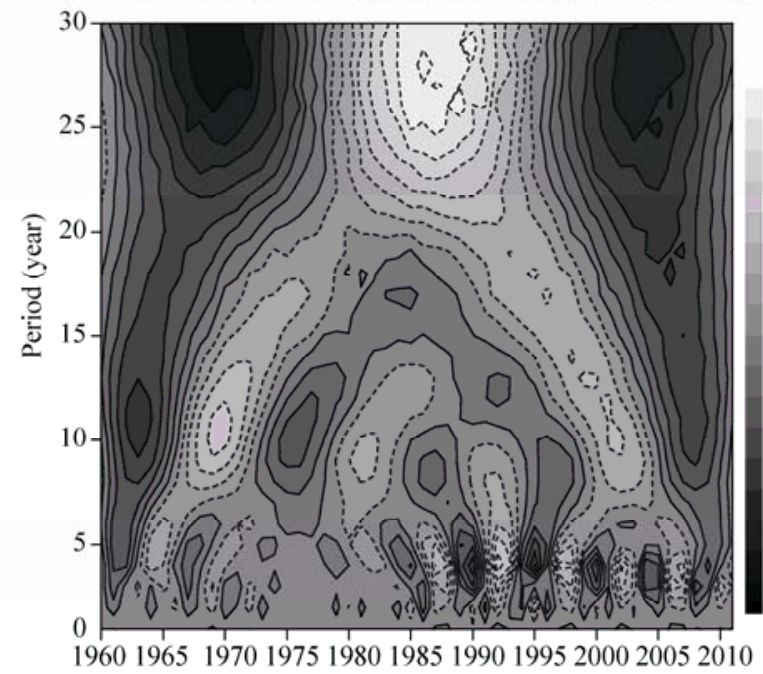

$-130.00$

$-115.00$

$-100.00$

$-85.00$

$-70.00$

$-55.00$

$-40.00$

$-25.00$

5.00

5.00
20.00

20.00
35.00

50.00

65.00

80.00

95.00

110.00

125.00

140.00

(cl) trends during the past 52 years in NX at a rate of -0.69 time/10a (Fig. 4a; $P<0.01$ ), and ranged from 0.97 to 8.55 times. During this period, there were 12 years that had drought occurrence of over 6 times, which occurred for 5 years during the 1960s $(7.82,8.13,8.32$,
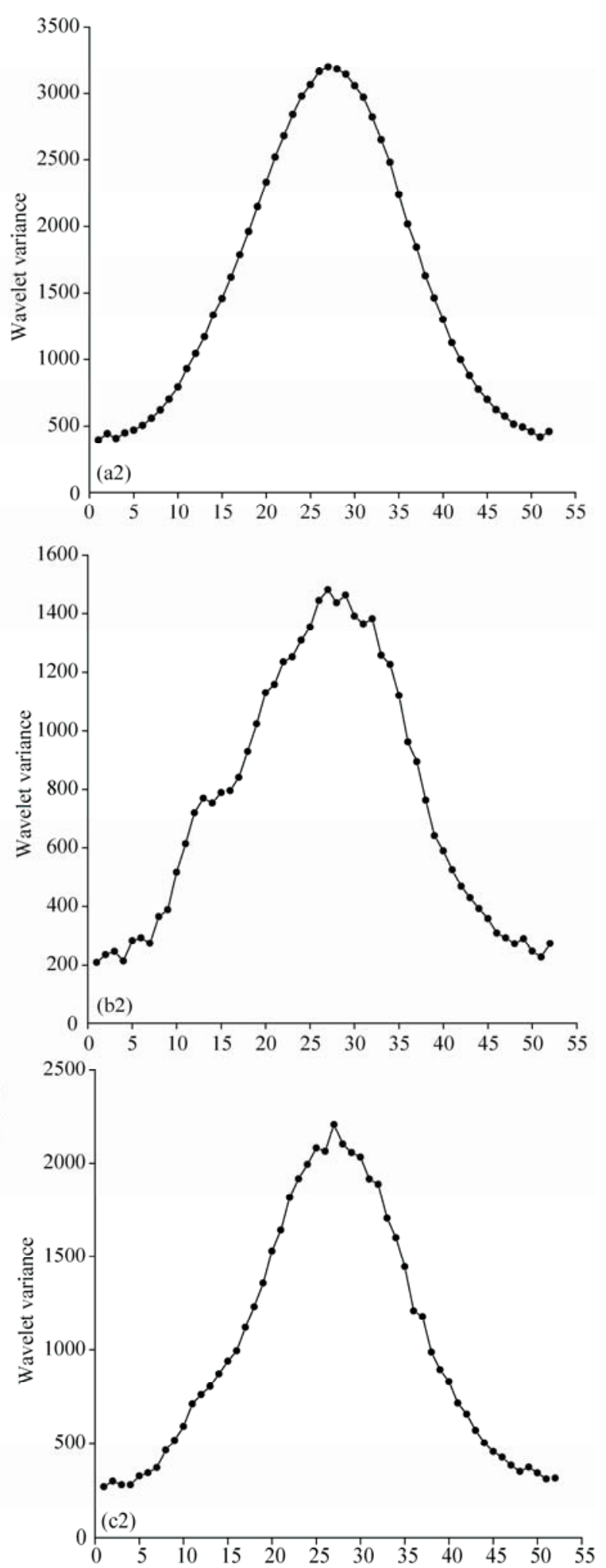

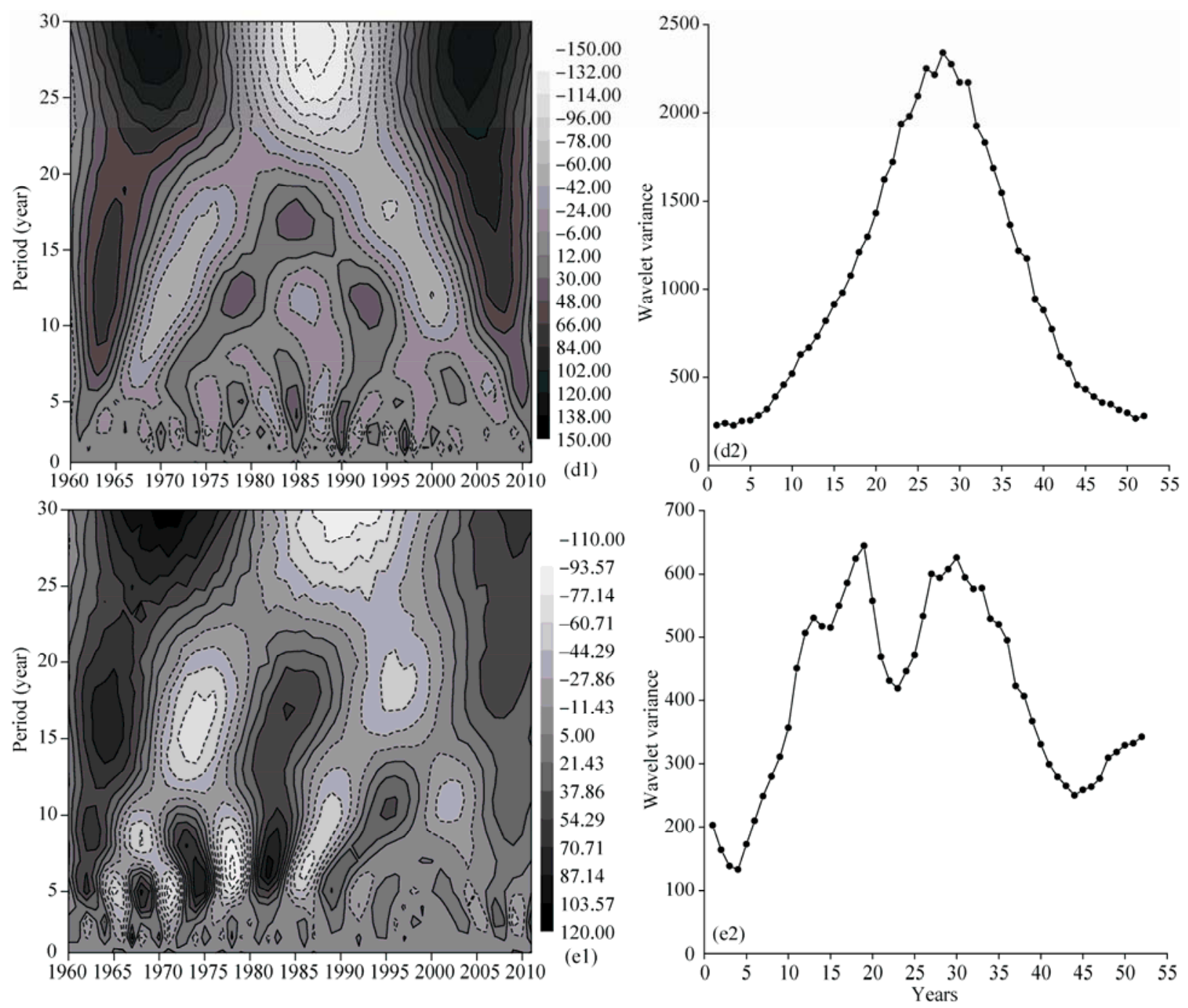

Fig. 3 Distribution of inter-annual (a1, a2) and seasonal (spring (b1, b2), summer (c1, c2), autumn (d1, d2) and winter (e1, e2)) drought occurrence on the real part of wavelet transform (left column) and the wavelet variances (right column) during the period of 1961-2012. In the left column, the dotted lines represent values less than zero and the real lines represent values greater than zero.

7.37 and 8.55 times for $1962,1963,1965,1967$ and 1968 , respectively), 3 years during the 1970s (7.92, 8.10 and 6.58 times for 1974, 1975 and 1977, respectively), 1 year during the 1980 s (7.76 times for 1982), 2 years during the 1990s (6.58 and 7.26 times for 1991 and 1997, respectively) and 1 year during the 2000s (8.16 times for 2008). Decadal drought occurrence exhibited a decreasing trend continuously from the $1960 \mathrm{~s}$ to the 2000s and achieved a minimum in the 2000s.

The drought occurrence of spring ranged from 0 to 2.95 times, and also exhibited a decreasing trend at a rate of -0.16 time/10a (Fig. $4 \mathrm{~b} ; P<0.05$ ). The occurrence was higher and exceeded 2.5 times in 1962, 1965, 1967, 1989 and 1997. There was no drought in 1998, and the drought duration was 0.08 month in 2010. The maximum decadal times for spring was 1.49 times in the 1960s and the minimum was 0.94 time in the 2000s.

The change trend of the summer drought occurrence was similar to the trend of spring, at a rate of -0.16 time/10a (Fig. $4 \mathrm{c} ; P<0.05$ ). The drought occurrence ranged from 0.03 to 2.87 times and reached 2.53, 2.74 and 2.87 times in 1962, 1968 and 2008, respectively. The times of summer drought occurrence were more from 1961 to 1987 with values ranging from 0.76 to 2.74 times, but varied significantly from 1988 to 2012 , with values ranging from 0.03 to 2.87 times. The decadal times of the summer drought occurrence displayed an increasing trend at first and then 

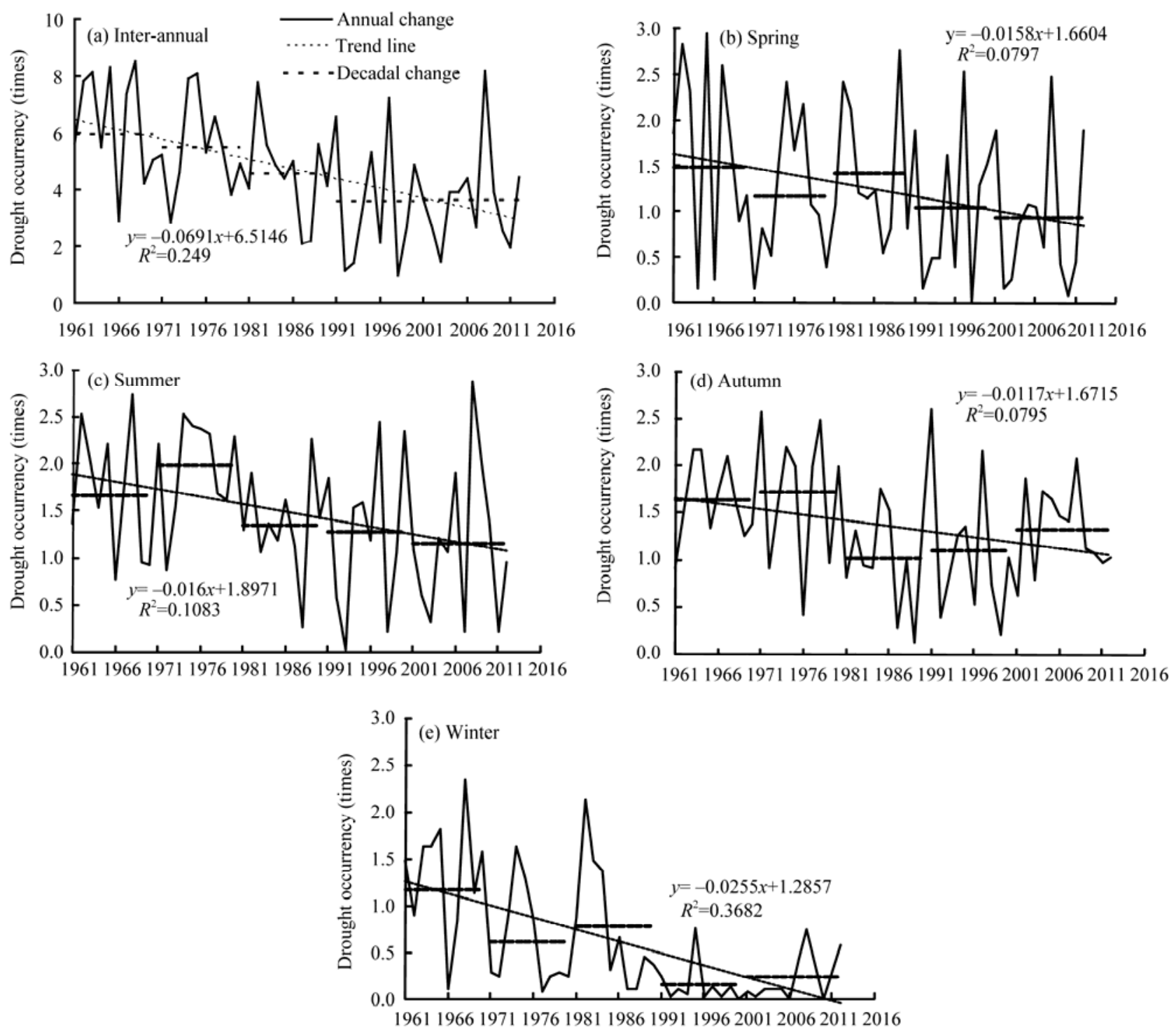

Fig. 4 Temporal variation of inter-annual (a) and seasonal ((spring (b), summer (c) autumn (d) and winter(e)) drought occurrence during the period of 1961-2012

followed a decreasing trend; it reached a maximum value of 1.98 times in the 1970 s and a minimum value of 1.15 times in the $2000 \mathrm{~s}$.

The decreasing trend of autumn drought occurrence was -0.12 time/10a (Fig. $4 d ; P>0.05$ ). The inter-annual variation of autumn drought occurrence exhibited a decreasing trend from 1961 to 1990 and an increasing trend from 1991 to 2012. In 1971, 1978 and 1991, the times of autumn drought occurrence were more and reached $2.58,2.5$ and 1.61 times, respectively, but in 1989 and 1999, the times of drought occurrence were short and reached 0.13 and 0.21 time, respectively. The characteristics of decadal change were similar, and reached a maximum value of 1.72 times in the 1970 s and a minimum value of 1.02 times in the $1980 \mathrm{~s}$.

The decreasing trend of winter drought occurrence was most significant, at a rate of -0.26 time/10a (Fig. $4 \mathrm{e} ; P<0.01)$. The times varied extensively from 0.07 to 2.34 months and the times of drought occurrence was more during 1961-1985. The frequencies had a narrow fluctuation from 0.07 to 2.34 times and the times of drought occurrence were less in 1986-2012. The decadal occurrence of winter reached a maximum value of 1.16 times in the 1960 s and a minimum value of 0.15 time in the 1990 s. 
2.2.2 Periodic characteristics of inter-annual and seasonal drought occurrence

Figure 5 shows the time-frequency distributions of the
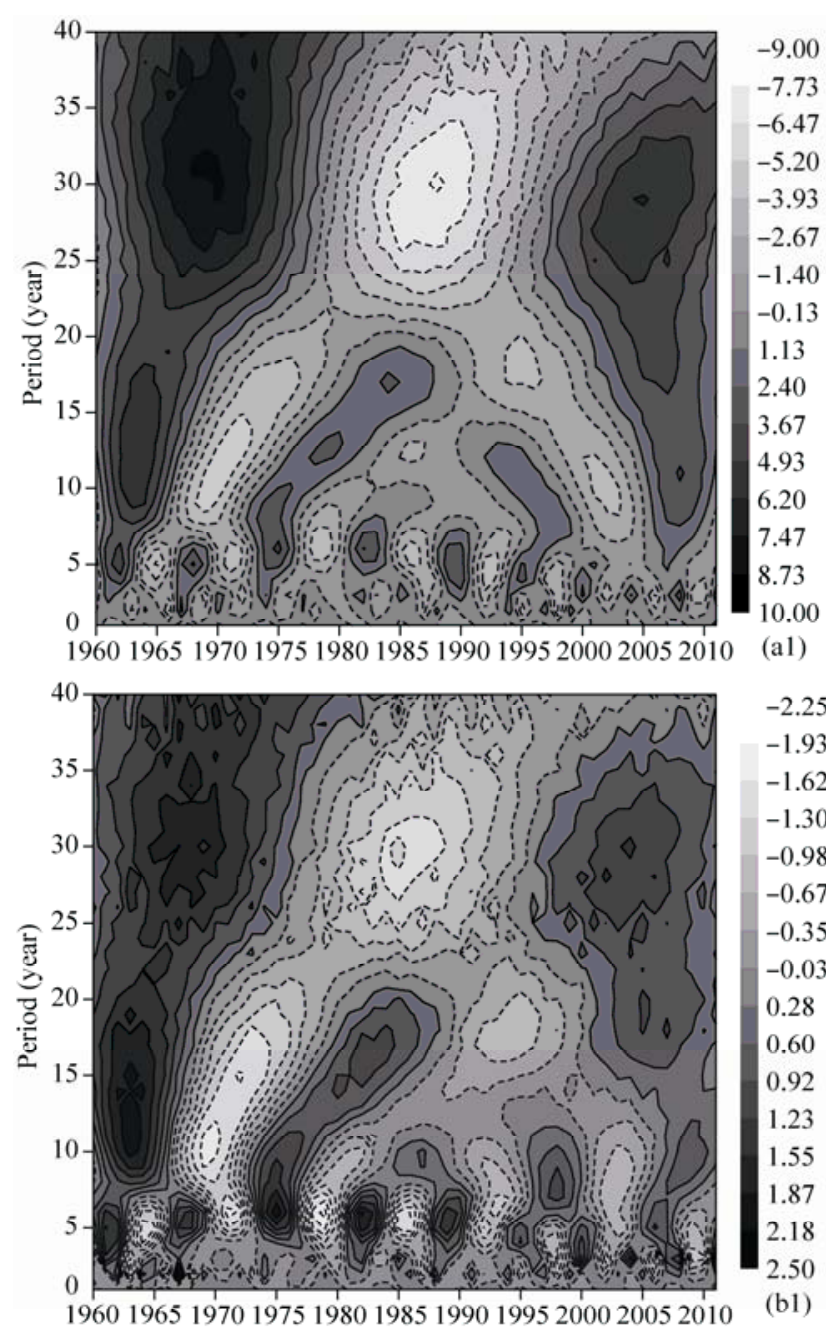

$-2.25$

$-2.25$

$-1.62$

$-1.30$

$-0.98$

$-0.67$

$-0.35$

$-0.03$

0.28

0.60

0.92

1.23

1.55

1.87

2.18

2.50

(b1)

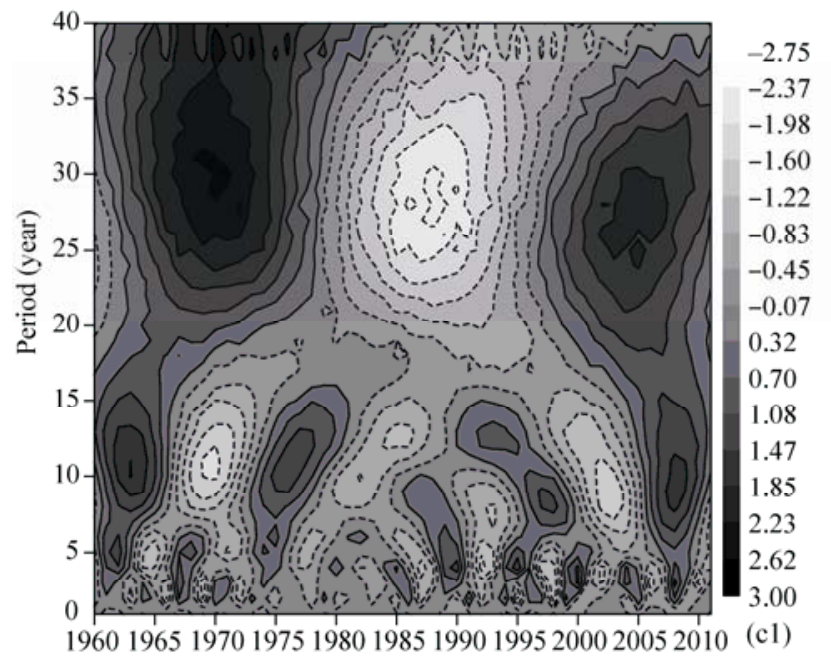

real part of the Morlet wavelet analysis and wavelet variances in the inter-annual and seasonal drought frequencies in NX. The inter-annual drought
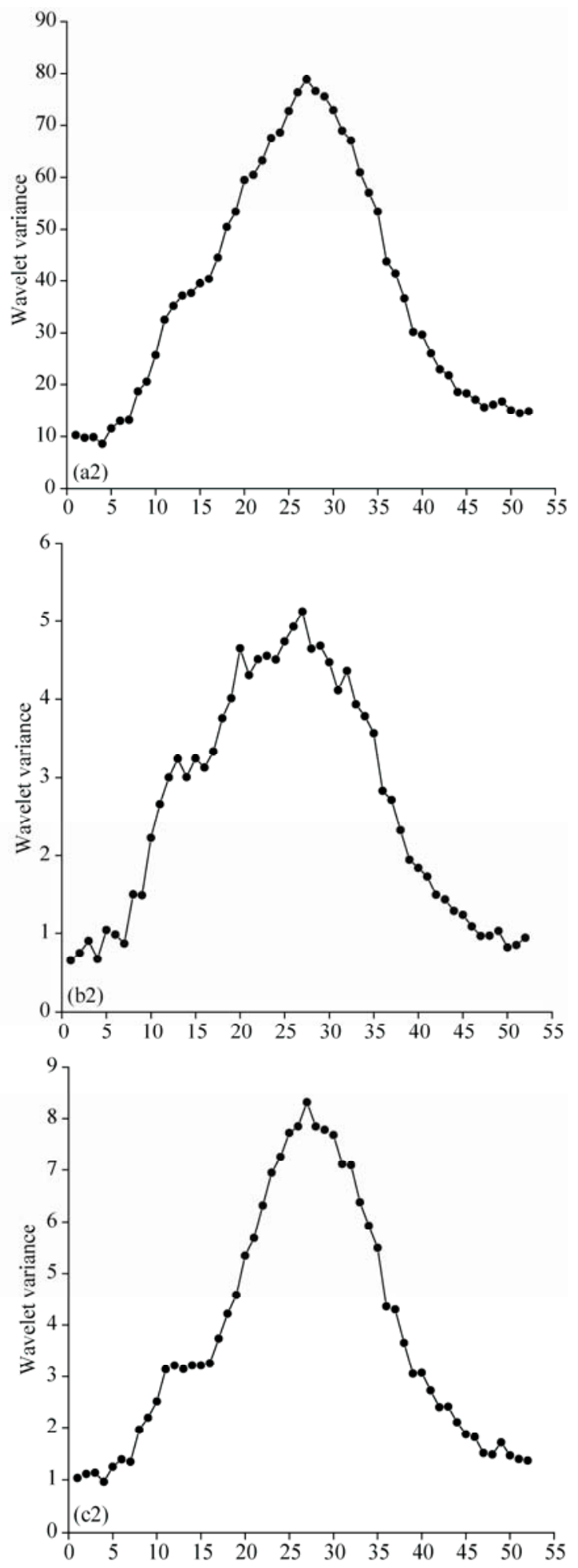

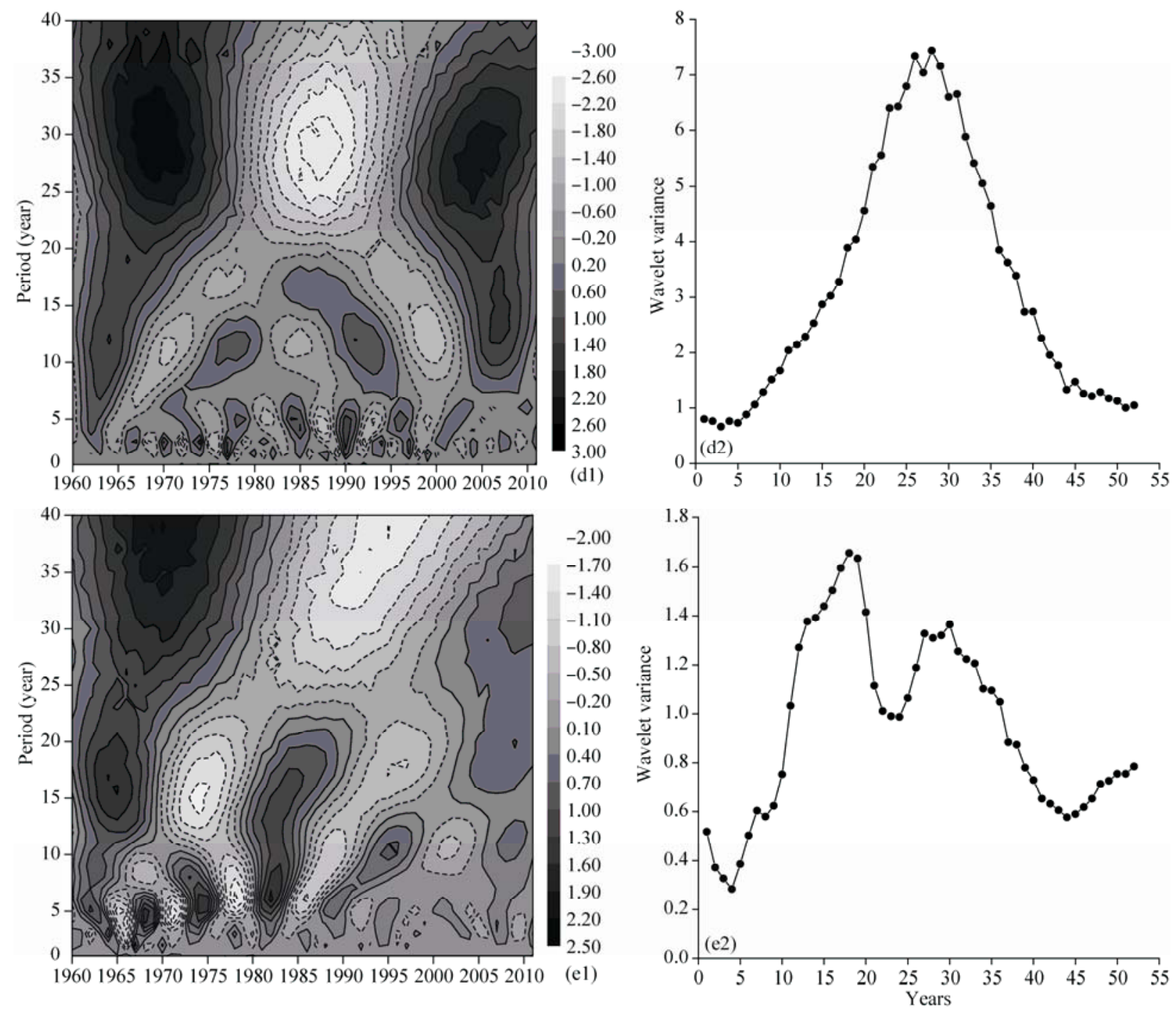

Fig. 5 Distribution of inter-annual (a1, a2) and seasonal (spring (b1, b2), summer (c1, c2), autumn (d1, d2), and winter (e1, e2)) drought occurrence on the real part of wavelet transform and the wavelet variances during the period of 1961-2012. In the left column, the dotted lines represent values less than zero and the real lines represent values greater than zero.

frequencies have periods of $29-30$ and 13.5 years, which developed intensively in the 1960s (Fig. 5a1). Clearly, only one peak value corresponds to the 27-year cycle (Fig. 5a2), which suggests that the major cycle of inter-annual drought coverage changes over 27 years during the past 52 years. The real part of the wavelet transform (Figs. 5b1, $\mathrm{c} 1$ and d1) and the wavelet variances (Figs. 5b2, c2 and d2) suggested that the drought frequencies of spring, summer and autumn all displayed periods of 29 years, which developed extensively in the 1960s. However, the drought times of winter (Figs. 5e1 and e2) displayed a period of 19 years, which developed extensively in the 1960s.

\subsubsection{Spatial characteristics of inter-annual and seasonal drought occurrence}

The spatial variations of inter-annual drought occurrence and change trends are shown in Figs. 6a and b, respectively. Overall, the average inter-annual drought occurrence of 38 meteorological stations ranged from 3.76 to 5.34 times. The relative minimum value appeared at Wenquan-Yumin-Hebukesaer-Jimunai; in particular, a minimum value of 3.4 times occurred at Wenquan. The times increased from the northwest to the southeast, and displayed two high value centers: Fuyun-Qinghe-Beitashan (5.17, 5.34 and 5.12 times, respectively) and Mosuowan-Paotai (5.21 and 5.17 times, respectively). The average inter-annual drought 

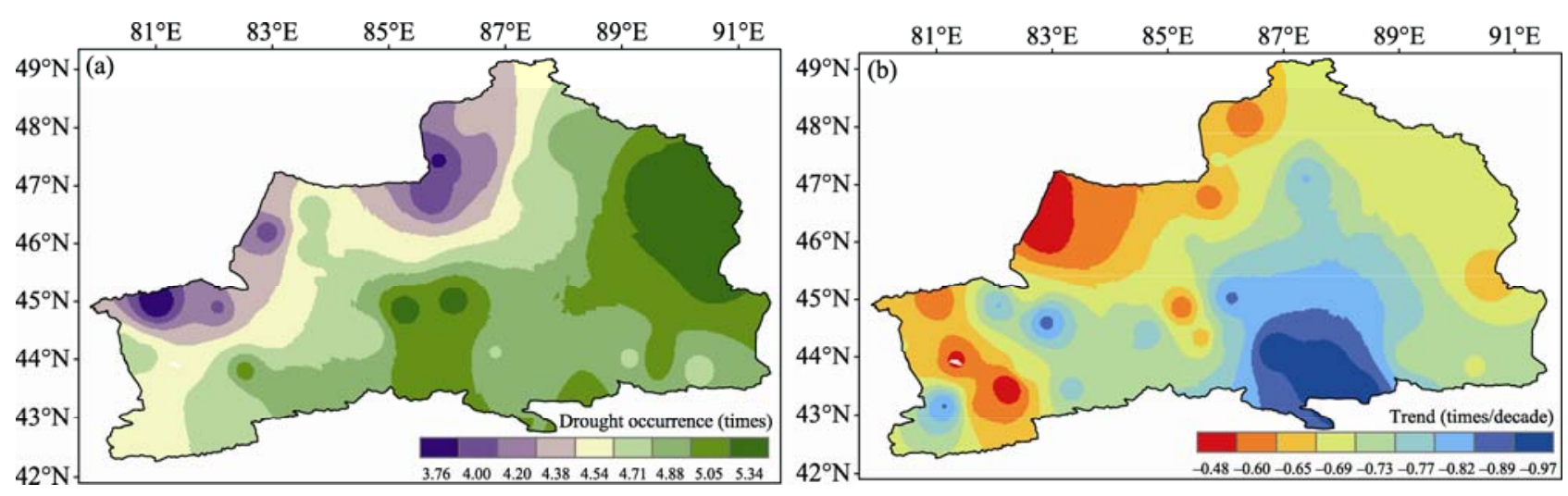

Fig. 6 Spatial variations of inter-annual drought occurrence (a) and change trend (b)

occurrence of 38 meteorological stations displayed an overall decreasing trend, especially in the significantly decreasing center of Urumqi-Dabancheng-Hutubi (Fig. 6b). Stronger decreasing trends were present in Dabancheng, Urumqi and Hutubi at the same rate of -1.05 times/10a.

Figure 7 illustrates the spatial variations of drought occurrence and change trends in spring (Figs. 7a and b), summer (Figs. 7c and d), autumn (Figs. 7e and f) and winter (Figs. $7 \mathrm{~g}$ and $\mathrm{h}$ ). The minimum value of drought occurrence times in spring appears in Wenquan-Bole-Yumin-Jimunai (Fig. 7a), and the average value of the four stations is 0.97 month. The times increased from the northwest to the southeast and displayed a high value center at Qinghe-Beitashan-Mulei, with a maximum value of 1.52 times. The average spring drought occurrence all displayed decreasing trends (Fig. 7b). A significantly decreasing center was located at Dabancheng-Qitai-Mulei, at rates of -0.33 , -0.25 and -0.23 time $/ 10 \mathrm{a}$, respectively. However, the higher values were located at Wenquan-YiningGongliu-Xinyuan, Shihezi, Fuyun and Tuoli, which indicated that the values of eastern and southeastern NX decreased more significantly than those of western NX.

Fuhai-Wusu-Gongliu can be divided into two regions in terms of summer drought occurrence times: the frequent drought region and the less frequent drought region (Fig. 7c). The higher values of the times were located at Fuyun-Qinghe- Hebukesaier and Shihezi-Urumqi and the lower values were located at Hebukesaier-Jimunai and Wenquan. Summer drought occurrence also exhibited a decreasing trend during the past 52 years (Fig. 7d). The most significant decreasing trends were located at Urumqi, Xinyuan and
Qinghe. The maximum value of the trend was -0.04 month/10a.

The spatial patterns of the times of drought occurrence in autumn are similar to those of summer, and all presented higher values at Shehezi and Qinghe and lower values in the northwest (Fig. 7e). The maximum value was 0.90 month in Wulanwusu and the minimum value was 1.62 months in Wenquan. The spatial distribution of the change trend values in autumn was opposite to that of the times (Fig. 7f). The spatial pattern of the middle region of NX with higher frequencies decreased more significantly, and the spatial pattern of the northwest region with lower times decreased insignificantly.

The occurrence of drought was relatively less in winter than in spring, summer and autumn (Fig. 7g). Fuyun-Qinghe-Beitashan located in the east had higher drought frequencies. The maximum value of the times was 0.96 month in Beitashan. From east to west and northwest, the times decreased continuously and displayed two lower value centers (Fig. 7h). The characteristics of change trend were more significant in the middle of NX and continuously tended to being insignificant from the middle to the east, north and west.

Drought occurrence and drought coverage are essential elements to evaluate variations of drought in regions (Pei et al., 2012). The decreasing trends of drought occurrence and drought coverage indicated that drought conditions in NX have an overall alleviating trend, which is consistent with previous results (Li et al., 2012; Zhao et al., 2012; Pan et al., 2013; Shao et al., 2014). 

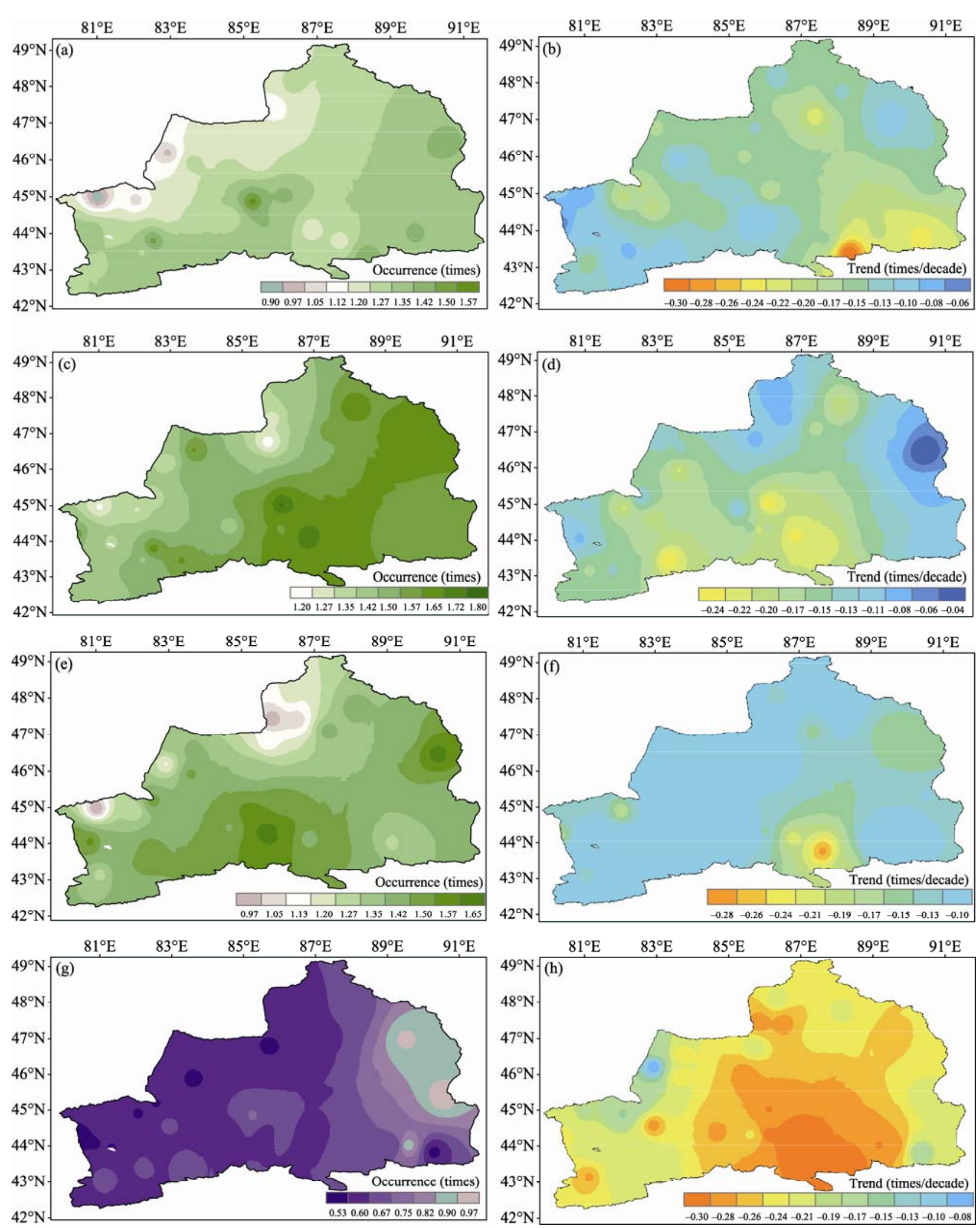

Fig. 7 Spatial variations of spring (a, b), summer (c, d), autumn (e, f), and winter (g, h) drought occurrence and change trend 
The occurrence of drought have direct relations with precipitation, temperature, wind speed, etc (Yao et al., 2011; Pei et al., 2013). The precipitation is concentrated in spring and summer in this area (Wang et al., 2013; Xu et al., 2014). However, the arid and windy climate in spring and the high temperature in summer cause more frequent drought in the two seasons (Sheffield et al., 2012; Vicente-Serrano et al., 2014).

The seasonal drought occurrence and changes indicated that drought was more serious in summer, moderate in autumn and spring, and mild in winter. In NX, snowautumn occurs mainly in winter and presented significant increasing trends (Li et al., 2013), which has great contributions to alleviate drought situation in winter. Spring and summer are the key stages of crop and vegetation growth in NX, therefore, further measures should be taken to benefit agricultural production and the ecological environment.

\subsubsection{EOF and REOF of drought occurrence}

Average annual drought occurrence was analyzed by EOF for dividing it into a spatial function and a chorological function. The first five eigenvalue convergences are fast and can be distinguished from each other. The proportions of variance explained by EOF of annual drought occurrence are given in Table 2 (Fig. 8). The accumulation variance contribution of the first two eigenvalues reached $74.42 \%$. Therefore, focusing on the spatial pattern of the first two eigenvalue convergences can adequately show the spatio-temporal patterns of drought in NX.

As shown in Table 2, the first mode accounts for $65.98 \%$ of the total eigenvalues and the eigenvalues are above zero, which indicates that the spatial characteristics of drought in NX have the same phase dis-

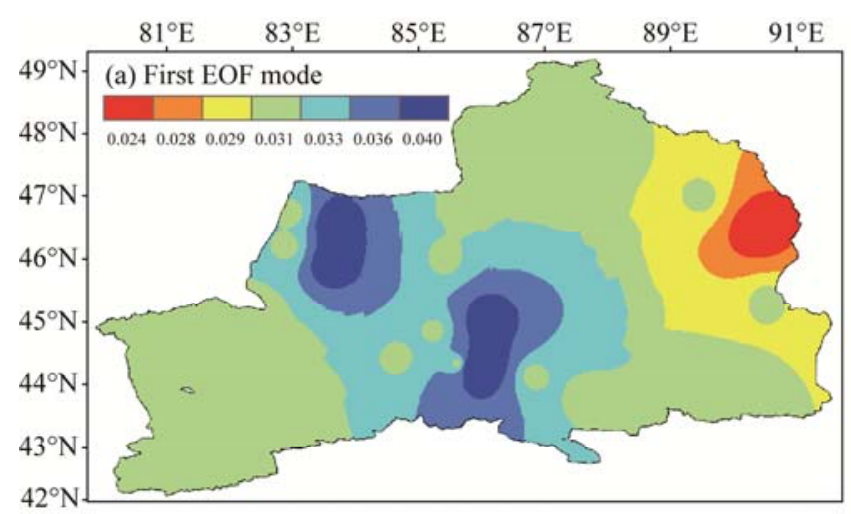

tribution and may be influenced by a global-scale weather system, such as westerlies (Zhou et al., 2012; $\mathrm{Xu}$ et al., 2014). The higher eigenvalues of this mode are mainly in Shihezi and Emin-Tuoli and the lower eigenvalues of this mode are mainly in Qinghe (Fig. 8a). The second mode accounts for $8.44 \%$ of the total eigenvalues and shows that the drought frequencies of the eastern and western regions are reversed (Fig. 8b). The reverse suggests that drought is more frequent in the east and less frequent in the west because the precipitation is greater in the west than in the east, but evaporation is less in the west than in the east (Pu et al., 2011).

For further understanding the spatial characteristics of drought occurrence in NX, we used REOF to analyze annual drought occurrence in different drought regions. The first four variance contributions are $39.09 \%, 30.76 \%, 21.51 \%$ and $8.64 \%$, respectively. It is generally assumed that the first REOF, whose accumulated variance is $39.09 \%$ of the total variance, has significance in explaining the original data (Kim et al., 2011; Song et al., 2014). Spatial analysis based on the first REOF suggested that NX can be divided into three different sub-regions in terms of drought: severe drought region (III), mild drought region (II) and moderate drought region ( I ) (Fig. 9), which indicated that the spatial distribution of drought occurrence differs greatly. The drought is severe in the eastern region, mild in the mid-west region and moderate in the central region of NX (Fig. 9), which is inconsistence with the spatial distribution of drought occurrence changes (Fig. 6b). This can cause serious challenges in terms of water resources management and lead to enormous demands for agricultural irrigation, especially in the eastern region of NX.

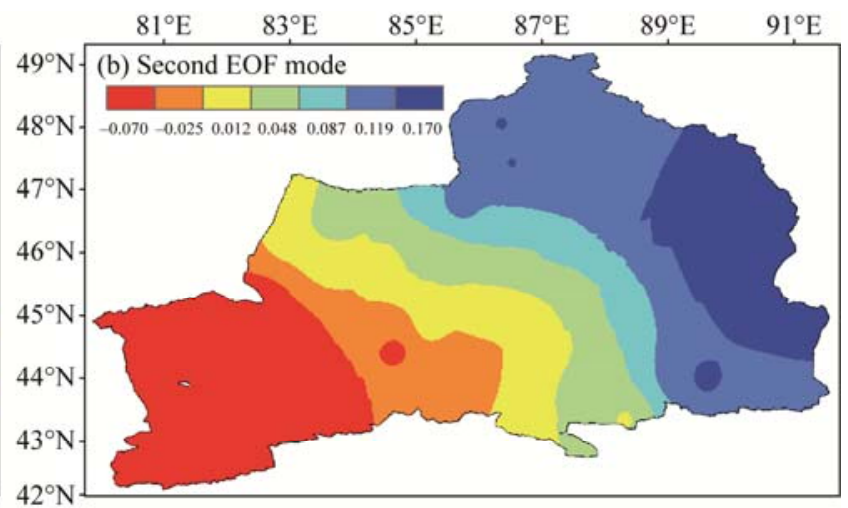

Fig. 8 Spatial distributions of annual drought occurrence in NX based on the first and second empirical orthogonal function (EOF) modes 
Table 2 Variance contribution of the front five characteristic vectors of annual drought occurrence

\begin{tabular}{lcrrrr}
\hline Mode & First & Second & Third & Fourth & Fifth \\
\hline Eigenvalue & 25.07 & 3.21 & 2.35 & 1.66 \\
Variance contribution (\%) & 65.98 & 8.44 & 6.18 & 4.37 \\
Accumulation variance contribution (\%) & 65.98 & 74.42 & 80.60 & 84.98 \\
\hline
\end{tabular}

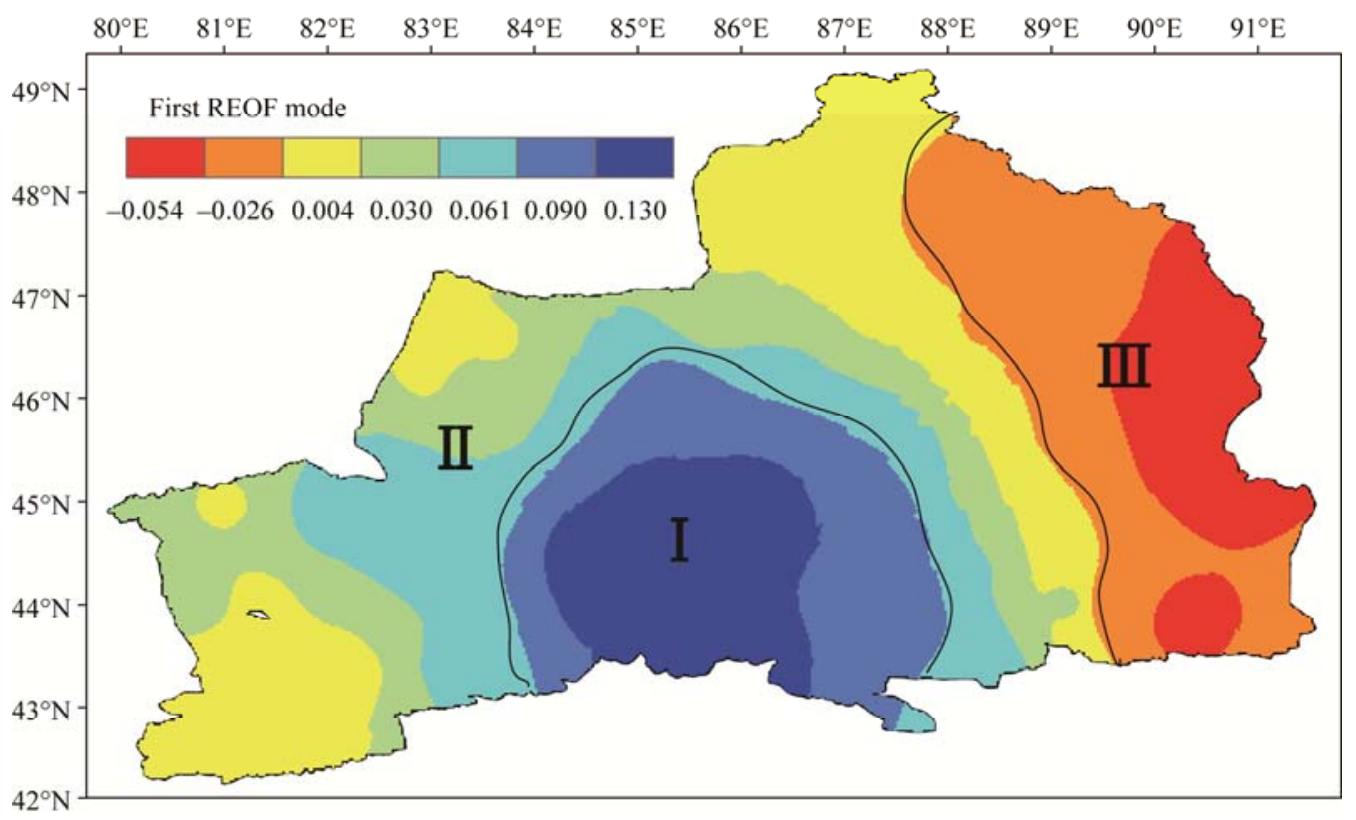

Fig. 9 Spatial distribution of annual drought occurrence based on the rotated empirical orthogonal function (REOF) mode

\subsection{Possible causes of drought changes}

Zhou et al. (2012) found that the variation of drought occurrence and drought coverage are influenced not only by regional meteorological factors but also by a global-scale weather system and adaptation to global change. Mahmood et al. (2010) suggested that the drought in Xinjiang were mainly caused by high sea level pressure, strong wind divergence, low convection of moisture and rare moisture availability. The precipitation of Altay Mountains, Junggar Basin and Tianshan Mountains exhibited increasing trends, which can be beneficial to the decreasing of drought occurrence and drought coverage in NX (Zhang et al., 2011; Dai et al., 2013). Another possible expiation of meteorological factors for the decreasing trend is the change of relative humidity and temperature (Yao et al., 2011). In the recent 52 years, there have been remarkable changes in the precipitation and potential evaporation in NX, the rates of which are strongly related to humidification and aridification (Yao et al., 2011; Li et al., 2014). As temperature is the major climatic factor influencing the exchange of substance and energy, increases in temperature in NX will result in increases of maximum potential evaporation, and reduction of precipitation, which in turn causes the reduction of the terrestrial surface humidity and the warming-drying tendency of climate. Whereas, the significant increase of precipitation in NX has more positive influence on the warming-wetting trend in NX (Shi et al., 2002).

On the other hand, the decreasing drought occurrence and drought coverage correlate with a globalscale weather system. The cross wavelet transform can be used to analyze the correlation between two time series by finding significant coherence even though the common power is low, and show how confidence levels against red noise backgrounds are calculated (Grinsted et al., 2004). Figure 10 shows the cross wavelet transform and squared wavelet coherence between $\mathrm{CI}$ and PNOI, NAOI, AOI, SOI and AAOI. The vectors in Fig. 10a indicated the phase difference between PNOI and $\mathrm{CI}$ at each time and period. The 

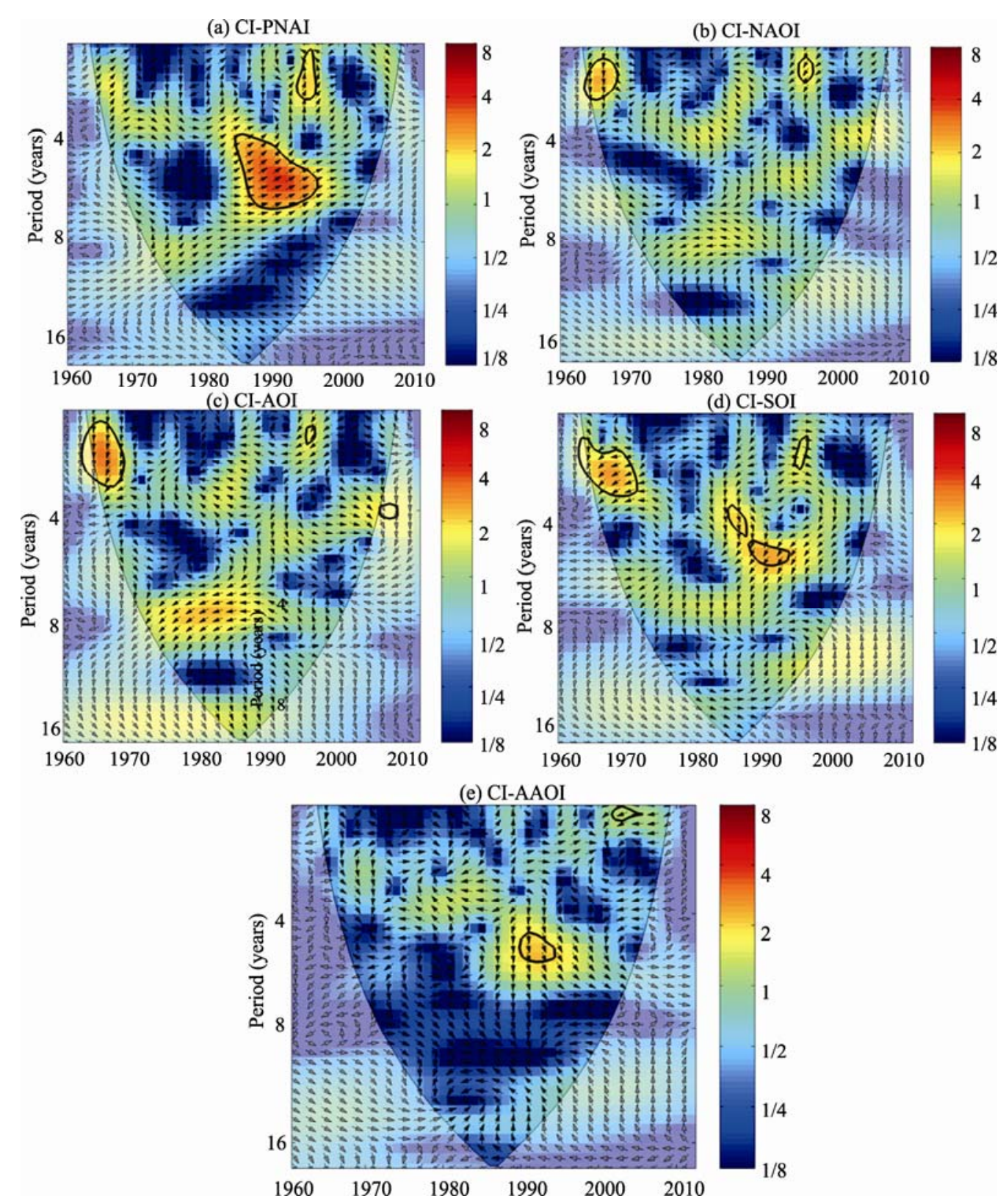

Fig. 10 The cross wavelet transform between $\mathrm{Cl}$ (composite index) and PNOI (Pacific/North American Oscillation Index, a), AOI (Arctic Oscillation Index, b), NAOI (North Atlantic Oscillation Index, c), SOI (Southern Oscillation Index, d) and AAOI (Antarctic Oscillation Index, e). The thick black contour designates a $5 \%$ significance level against red noise; the relative phase relationship is shown as arrows, with in-phase pointing right and anti-phase pointing left.

positive and negative correlation between $\mathrm{CI}$ and PNOI transformed more frequently in smaller periods. High power and coherence associated significantly with signals at 4-7a timescales from the mid-1980s to the late $1990 \mathrm{~s}$ and at $1.5-2.5 \mathrm{a}$ timescales in the late 1990s. The negative correlation was more significant before 1970s, whereas, the positive correlation was more significant after 1970s in 1-8a periods. Simultaneously, the negative correlation was more signifi- cant before 1980s and the positive correlation was more significant after 1980s during 8-16a periods.

Cross wavelet transform (Fig. 10b) indicated larger covariance between NAOI and CI indices at scales of $1.5-2.5 \mathrm{a}$ from the mid-1960s to the late $1990 \mathrm{~s}$ and 1.5-2.0a in the mid-1960s. Frequent transformation of the positive and negative correlation between $\mathrm{CI}$ and NAOI occurred in 1-8a periods. Whereas, CI mainly had negative correlation with NAOI in 8-16a periods. 
The cross wavelet transform between CI and AOI (Fig. $10 \mathrm{c})$ suggested that the $5 \%$ confidence significance level was mainly distributed in 1.5-3.0a periods during $1962-1970$ and in $2.0-2.5 \mathrm{a}$ periods in the late 1990s. The cross wavelet transform between CI and SOI is shown in Fig. 10d. The CI and SOI showed significance in the 1.5-3.5a, 4.0-5.0a and 5.5-6.5a bands. Unlike PNOI, NAOI, AOI and SOI, the significant correlation between AAOI and CI (Fig. 10e) mainly happened in 5-6a periods during 1990-1994.

\section{Conclusions}

In this paper, we investigated the spatio-temporal patterns of drought in NX during the past 52 years. At the temporal scale, inter-annual drought coverage and drought occurrence displayed decreasing trends. The drought coverage and drought occurrence in winter decreased most significantly, those in spring and summer decreased relatively significantly, and the autumn decrease was insignificant. Overall, the inter-annual drought coverage has a 27 -year period and the inter-annual drought occurrence has a 29 -year period.

Spatially, the drought conditions were serious in Qinghe, Beitashan and Fuyun, moderate in Shihezi, and mild in Yili, Bortala and Tacheng. The decreasing trends were most significant in Shihezi, Urumqi and Changji, which helped to alleviate severe drought hazards. Moreover, three sub-regions were divided in terms of drought conditions: severe drought region, moderate drought region and mild drought region. The cross wavelet transform suggested that the climate fluctuations reflected from PNOI, AOI, NAOI, SOI and AAOI have significant correlation with the variations of drought times at different periodic scales in NX.

The results of the spatio-temporal pattern of drought occurrence indicated that the significantly alleviating tendency of drought is in good agreement with the wetting tendency in NX. However, the uneven spatial patterns of drought resulted from the imbalanced spatio-temporal changes of meteorological factors and spatial water resources and irrigation conditions also have massive impacts on the local irrigation agriculture, especially in spring and summer. Therefore, the further development of water resources management for irrigation systems will be critical to the mitigation of drought effect.
Our analyses can provide further knowledge to improve our understanding of the effect of climate change on drought occurrence. The results would be useful for future planning to maintain water resources safety, especially under the background of global warming.

\section{Acknowledgements}

This study was supported by International Science \& Technology Cooperation Program of China (2010DFA92720), the Scientific Innovation Research Project for Graduate Students of Xinjiang, and Soil Science Key Discipline Project of Xinjiang Uygur Autonomous Region.

\section{References}

Cao L G, Pan S M, Wang Q, et al. 2014. Changes in extreme wet events in Southwestern China in 1960-2011. Quaternary International, 321: 116-124.

Cao X, Wan Y, Cui Y L, et al. 2013. Analysis on change tendency of relative moisture index in northern piedmont of middle Tianshan Mountain over recent 30 years. Agricultural Research in the Arid Areas, 31(3): 244-251. (in Chinese)

Dai A G. 2013. Increasing drought under global warming in observations and models. Nature Climate Change, 3(1): 52-58.

Dai X G, Wang P, Zhang K J. 2013. A study on precipitation trend and fluctuation mechanism in northwestern China over the past 60 years. Acta Physica Sinica, 62(12): 1-11. (in Chinese)

Easterling D R, Meehl G A, Parmesan C, et al. 2000. Climate extremes: observations, modeling, and impacts. Science, 289: 2068-2074.

Gong P, Sun J L, Gong Y S. 2013. Long-term change characteristics of gale days on the Yellow Sea. Modern Agricultural Science and Technology, (12): 185-187. (in Chinese)

Grinsted A, Moore J C, Jevrejeva S. 2004. Application of the cross wavelet transform and wavelet coherence to geophysical time series. Nonlinear Processes in Geophysics, 11(5/6): 561-566.

Jiang F Q, Hu R J. 2004. Climate change and expanded flood control and drought disasters in nearly 50 years in Xinjiang province. Journal of Desert Research, 24(1): 35-40. (in Chinese)

Katz R W, Brown B G. 1992. Extreme events in a changing climate: variability is more important than averages. Climate Change, 21(3): 289-302.

Keyantash J, Dracup J A. 2002. The quantification of drought: an evaluation of drought indices. Bulletin of the American Meteorological Society, 83(8): 1167-1180.

Kim D H, Yoo C, Kim T W. 2011. Application of spatial EOF and multivariate time series model for evaluating agricultural drought vulnerability in Korea. Advances in Water Resources, 34(3): 340-350.

Li B Z, Zhou G S. 2014. Advance in the study on drought index. Acta Ecologica Sinica, 34(5): 1043-1052. (in Chinese)

Li J F, Zhang Q, Chen X H, et al. 2012. SPI-based drought variation in Xinjiang, China. Journal of Applied Meteorological Science, 23(3): 322-330. (in Chinese) 
Li X S. 2013. Changing characteristics of snowautumn in Xinjiang from 1961 to 2010. PhD Dissertation. Lanzhou: Northwest Normal University. (in Chinese)

Li Z, Cheng Y N, Yang J, et al. 2014. Potential evapotranspiration and its attribution over the past 50 years in the arid region of Northwest China. Hydrological Processes, 28(3): 1025-1031.

Liu Y L, Yu H M. 2012. Drought changes of critical period of crop growth in Heilongjiang province based on $\mathrm{CI}$ index. Journal of Meteorology and Environment, 28(1): 48-54. (in Chinese)

Mahmood R, Li S L, Khan B. 2010. Causes of recurring drought patterns in Xinjiang, China. Journal of Arid Land, 2(4): 279-285.

McKee T B, Doesken N J, Kleist J. 1993. The relationship of drought frequency and duration to time scales. In: Proceedings of the $8^{\text {th }}$ Conference on Applied Climatology. Boston: American Meteorological Society, 179-184.

McKee T B, Doesken N J, Kleist J. 1995. Drought monitoring with multiple time scales. In: Proceedings of the $9^{\text {th }}$ Conference on Applied Climatology. Boston: American Meteorological Society, 233-236.

Palmer W C. 1965. Meteorological Drought. Washington: US Department of Commerce, Weather Bureau.

Pan S K, Zhang M J, Wang B L, et al. 2013. Study on the drought index variation for Xinjiang in recent 51 years. Journal of Arid Land Resource and Environment, 27(3): 32-39. (in Chinese)

Pei Y S, Jiang G Q, Zhai J Q. 2013. Theoretical framework of drought evolution driving mechanism and the key problems. Advance in Water Science, 24(3): 449-456. (in Chinese)

Pu Z C, Zhang S Q. 2011. Spatial-temporal variation of dry-wet climate on summer in recent 48 years in Xinjiang. Journal of Arid Land Resource and Environment, 35(1): 23-31. (in Chinese)

Shafer B A, Dezman L E. 1982. Development of a Surface Water Supply Index (SWSI) to assess the severity of drought conditions in snowpack runoff areas. In: Proceedings of the Western Snow Conference. Colorado: Colorado State University, 164-175.

Shao J, Li Y. 2014. Spatiotemporal distribution and variation of drought and waterlog in different time scales in Sinkiang. Journal of Irrigation and Drainage, 33(1): 68-73. (in Chinese)

Sheffield J, Wood E F, Roderick M L. 2012. Little change in global drought over the past 60 years. Nature, 491(7424): 435-438.

Shi Y F, Shen Y P, Hu R J. 2002. Preliminary study on signal, impact and foreground of climatic shift from warm-dry to warm-humid in northwest China. Journal of Glaciology and Geocryology, 24(3): 219-226. (in Chinese)

Song X Y, Li L J, Fu G B, et al. 2014. Spatial-temporal variations of spring drought based on spring-composite index values for the Songnen Plain, Northeast China. Theoretical and Applied Climatology, 116(3-4): 371-384.

Stocker T, Qin D, Plattner G K, et al. 2014. Climate Change 2013: The Physical Science Basis. Cambridge and New York: Cambridge University Press.

Valdés-Galicia J F, Velasco V M. 2008. Variations of mid-term periodicities in solar activity physical phenomena. Advances in Space Research, 41(2): 297-305.

Vicente-Serrano S M, Lopez-Moreno J I, Beguería S, et al. 2014. Evidence of increasing drought severity caused by temperature rise in southern Europe. Environmental Research Letters, 9(4): 044001.

Wang B L, Zhang M J, Wei J L, et al. 2013. Changes in extreme events of temperature and precipitation over Xinjiang, northwest China, during 1960-2009. Quaternary International, 298: 141-151.

Wang Y Y, Zhang B. 2012. Analysis of drought-flood spatial-temporal characteristics based on standard precipitation index in east region of Gansu in recent 40 years. Journal of Natural Resources, 27(12): 2135-2144. (in Chinese)

Xie W S, Tian H, Wang S, et al. 2013. Study on spatial-temporal characteristics of drought in Huaihe River Basin based on CI index. Meteorological Monthly, 39(9): 1171-1175. (in Chinese)

Xu C C, Li J X, Zhao J, et al. 2014. Climate variations in northern Xinjiang of China over the past 50 years under global warming. Quaternary International, 358: 83-92.

Yang J H, Jiang Z H, Liu X Y, et al. 2012. Influence research on spring vegetation of Eurasia to summer drought-wetness over the northwest China. Arid Land Geography, 35(1): 10-21. (in Chinese)

Yang L, Wong C M, Lau E H Y, et al. 2008. Synchrony of clinical and laboratory surveillance for influenza in Hong Kong. PLoS ONE, 3(1): e1399.

Yao Y B, Yang J H, Yue P, et al. 2011. Climatic change of terrestrial surface humid index and its impact factors over the source region of three rivers in recent 50 years. Ecology and Environmental Sciences, 20(11): 1585-1593.

Yu X G, He X Y, Zheng H F, et al. 2014. Spatial and temporal analysis of drought risk during the crop-growing season over northeast China. Natural Hazards, 71(1): 275-289.

Zhang M J, He J Y, Wang B L, et al. 2013. Extreme drought changes in Southwest China from 1960 to 2009. Journal of Geographical Sciences, 23(1): 3-16.

Zhang Q, Sun P, Li J F, et al. 2014. Spatiotemporal properties of droughts and related impacts on agriculture in Xinjiang, China. International Journal of Climatology, doi: 10.1002/joc.4052.

Zhang S Q, Pu Z C. 2011. Temporal and spatial variation characteristics of reference evapotranspiration in Xinjiang. Transactions of the Chinese Society of Agricultural Engineering, 27(5): 73-79. (in Chinese)

Zhang T F, Zhang B, Wang Y H, et al. 2013. Drought characteristics in the shiyang river basin during the recent 50 years based on a composite index. Acta Ecologica Sinica, 33(3): 975-984. (in Chinese)

Zhang X Q, Lei Y C, Pang Y, et al. 2014. Tree mortality in response to climate change induced drought across Beijing, China. Climatic Change, 124(1-2): 179-190.

Zhao Y, Yang Q, Ma Y F. 2012. Analysis on features of regional and continuous drought in North Xinjiang in spring and summer. Arid Zone Research, 29(3): 472-478. (in Chinese)

Zhao Z P, Liu J Y, Shao Q Q. 2010. Spatial diversity of humidification and its impact on ecosystem venerability in china during the last 30 years. Journal of Natural Resources, 25(12): 2091-2100. (in Chinese)

Zhou S W, Wang C H, Wu P, et al. 2012. Temporal and spatial distribution of strong precipitation days over the Tibetan Plateau. Arid Land Geography, 35(1): 23-31. (in Chinese)

Zhuang X C, Yang S, Zhao Z B, et al. 2010. Drought index and its application in the analysis on drought monitoring in Altai Region, Xinjiang. Journal of Catastrophology, 25(3): 81-85. (in Chinese) 